\title{
BOA VONTADE, DEVER E RESPEITO NA FUNDAMENTAÇÃO I
}

\author{
Quesidonis Felipe da Silva \\ Universidade de São Paulo
}

Resumo: 0 objetivo deste artigo é a discussão da função de três conceitos na Fundamentação da metafísica dos costumes, de Kant: boa vontade, dever e respeito. Na primeira secção da Fundamentação, Kant opera a transição ou passagem do conhecimento racional moral comum para o conhecimento filosófico. 0 ponto de partida do autor, o conhecimento racional moral comum, reserva interesse especial. Embora esta noção seja identificada como ponto de partida na obra, não temos nenhuma exposição esclarecendo seu significado, mas, noutro sentido, a apresentação da boa vontade como aquilo que deve ser considerado como bom sem restrição. A apresentação da boa vontade constitui, como observa H. J. Paton, antes uma exposição de um princípio moral adotado por um sujeito previamente, mesmo que de maneira inconsciente, do que um juízo moral da razão comum. Neste sentido, se a consideração da boa vontade como irrestritamente boa não atende à função de ponto de partida da investigação, é necessário discutir qual é o verdadeiro ponto de partida, bem como seu desenvolvimento nos conceitos de boa vontade, dever e respeito. Assim, este trabalho será dividido em três momentos: no primeiro momento, investigamos o conceito de boa vontade, no segundo, exploramos o conceito do dever e sua relação com a boa vontade enquanto ponto de partida da investigação da Fundamentação, também exploramos as opções tradicionais de interpretação da primeira e segunda proposições sobre a ação moral; por fim, no terceiro momento, discutimos o conceito de respeito, bem como 0 processo de universalização da máxima e a racionalidade desta operação. De modo geral, este trabalho tenta responder (i) qual é validade do processo de universalização da máxima na primeira secção e (ii) qual a função das três proposições neste processo. Argumenta-se, na linha contrária à interpretação de R. P Wolff, que não é necessário conceber a primeira secção como separada do restante da obra, mas, ao contrário, ela constitui uma parte fundamental, sendo a primeira exposição sistemática do princípio moral kantiano (o imperativo categórico) como pertencendo à razão humana comum e sendo independente de qualquer elemento histórico ou social.

Palavras-chave: Kant. Boa Vontade. Dever. Respeito.

\footnotetext{
${ }^{1}$ Mestrando em Filosofia. Agência financiadora da pesquisa: Fundação de Amparo à Pesquisa do Estado de São Paulo (FAPESP). E-mail: quesidonis.silva@usp.br.
}

\section{Blucher}


Quesidonis Felipe da Silva

Good Will, duty and respect in Groundwork I

Abstract: The aim of this article is the discussion about the function of three concepts in Kant's Groundwork of Metaphysics of Morals: good will, duty and respect. In the first section of the GMS, Kant makes the transition between the common moral rational knowledge and the philosophical one. Kant's start point, identifying with the common moral rational knowledge, reserve our attention. Although this notion being identified with this function, the begin of this section do not make the exposition about what should be understood as it, but, in another way, make the exposition of the good will as the only thing that we can considerer as good without restriction. This operation is, as H. J. Paton said, more properly, in an exposition of a moral principle adopted for a subject, even if unconsciously, than an judgment of the common man. In this way, if the considerations of the good will like good without restrictions do not attend this function in GMS, there is the necessity of a discussion on what is the actual start point in the investigations, as well as its development in the concepts of good will, duty and respect. Thus, this work was divided in three parts: in the first, we make the investigation of concept of good will; in the second, we explore the concept of duty and its relation with the good will as a start point in the GMS's investigation and we explore the option of the interpretation in the tradition and the possibilities of formulation of the first and second propositions; in the third part, we make the discussion of the concept of respect, as well as the process of universalization of maxim and the rationality of this project. In a general consideration, this work aims to respond (i) what is the reason and validity of the process of universalization of maxim in the first section and (ii) what is the function of the "three propositions" in universalization of maxim. Our argumentation search to prove that contrary to R. P. Wolff's perspective, it is not necessary to conceive the first section of the GMS as separated of the rest of the work. However, in an integrated perspective of Kant's work, we think that this section is very important for the GMS because we see a systematic exposition of the Kantian moral principle (the categorical imperative) between a common human faculty and independent of any social construction.

Keywords: Kant. Good Will. Duty. Respect. 
A primeira seção da Fundamentação da metafísica dos costumes, de Kant, opera a transiç̧ão ou passagem (Übergang) do conhecimento racional moral comum para o conhecimento filosófico. 0 ponto de partida de Kant, identificado como o "conhecimento racional moral comum", requer atenção. Isso porque, apesar de identificá-lo como ponto de partida, 0 início desta seção não explicita o que deve ser entendido como o conhecimento racional moral comum, mas, em outro sentido, faz a determinação e explicitação da boa vontade como aquilo que é unicamente bom sem restrições. Algo que, como observa H. J. Paton, mais parece com um princípio moral anteriormente adotado pelo sujeito, mesmo que inconscientemente, do que com um tipo de juízo que o "homem comum" normalmente executa (PATON, 1971, p. 34). Ora, se as considerações da boa vontade não se encaixam satisfatoriamente nesta função, faz-se necessário discutir aquilo que é, propriamente, o ponto de partida da investigação, bem como seus desdobramentos nos conceitos de dever e respeito. Neste sentido, este trabalho será divido em três partes: na primeira parte investigamos 0 conceito de boa vontade; na segunda parte discutimos o conceito de dever, sua ligação com a boa vontade e de que modo ela se dá como o ponto de partida enquanto conhecimento racional moral comum; na terceira parte tratamos do conceito de respeito e da universalização da máxima. Em linhas gerais, buscamos responder: (i) qual a legitimidade da universalização da máxima que se opera nesta seção e (ii) de que modo as "três proposições", nela apresentadas, podem ser compreendidas como este processo de universalização. A argumentação visa demonstrar que, ao contrário da proposta de R. P. Wolff, que pensou em excluir esta seção do projeto de Fundamentação, ela é de fundamental importância, dado que nela temos, pela primeira vez, uma exposição sistemática e coerente do imperativo categórico a partir de certa faculdade comum ao gênero humano e independentemente de qualquer construção social. 
"Não há nada em lugar algum, no mundo e até mesmo fora dele, que se possa pensar como sendo irrestritamente bom, a não ser tão-somente uma boa vontade" (KANT, 2009, p. 101). A apresentação da boa vontade 2 possui, a princípio, caráter de exceção em relação a uma regra geral. Enquanto tal, a boa vontade não recebe nenhuma característica positiva e o tipo de apresentação envolvida conota apenas uma representação geral do pensar. Ao pensar, o sujeito não consegue conceber nada que seja bom sem restrições, isto é, bom em todos os casos possíveis de serem pensados, salvo a boa vontade. Este ponto de partida, contudo, mais parece o resultado da argumentação que segue a apresentação da boa vontade e que, em um esforço de exposição, demonstra como outros aspectos do sujeito, apesar de bons, não podem ser ditos irrestritamente bons. Os três aspectos examinados são: (i) os talentos da mente, (ii) as propriedades do temperamento e (iii) os dons da fortuna. Sobre eles, Kant diz serem "coisas boas e desejáveis sob vários aspectos, mas podem também tornar-se más e nocivas se não é boa a vontade que deve fazer uso desses dons [...]" (KANT, 2009, p. 101). Os talentos da mente - entendimento, engenho, faculdade de julgar (Urteilskraft) - são pensados por Kant como dons da natureza, isto é, um certo tipo de excelência do sujeito que independe da instrução na qual o engenho, enquanto faculdade de excogitar o universal do particular, emparelharia representações heterogêneas e, via faculdade de julgar, encontraria o particular sob o universal com o objetivo de formar o conhecimento (KANT, 2006, p. 29). As propriedades do temperamento, por sua vez, não constituem um tipo de

\footnotetext{
${ }^{2}$ Segundo Victor Delbos (DELBOS, 1969, p. 259) e Guido de Almeida (ALMEIDA, 2009, p. 52), a origem do termo boa vontade na filosofia moral kantiana é, em geral, atribuída ou a uma adoção a partir do estoicismo (Sêneca, De Vita, III) ou a adoção do termo a partir dos Evangelhos (Lucas 2,14). Ambas as leituras são plausíveis, a primeira, por expor uma sabida ligação entre Kant e 0 estoicismo (especialmente Cícero), a segunda, por reforçar sua ligação com a moral cristã, via puritanismo.
} 
excelência natural do sujeito aos moldes dos talentos da mente, mas propriedades que estariam ligadas ao ânimo nas ações, como é o caso da coragem, da decisão e da persistência do propósito. Já os dons da fortuna - poder, riqueza, honra, saúde e bem-estar - carregam elementos mais físicos ou corpóreos. Deste modo, podemos dividir estes aspectos do sujeito sob as rubricas de: (i) aspectos (excelências) intelectuais, (ii) aspectos do ânimo e (iii) aspectos físicos.

Kant atribui 0 adjetivo de bons a todos estes aspectos, contudo, nenhum deles pode ser pensado como bom sem restrições, porque todos podem ser utilizados em condutas más ou perversas. Não por outro motivo Kant afirma que, apesar de boas, elas são fontes de soberba quando não há uma

[...] boa vontade para corrigir sua influência sobre 0 ânimo e, ao mesmo tempo, [sobre] todo o princípio do agir, tornando-os assim conformes a fins universais; para não mencionar o fato de que um espectador imparcial e racional jamais pode se comprazer sequer com a vista da prosperidade ininterrupta de um ser a quem não adorna traço algum de uma vontade boa e pura e, assim, que a boa vontade parece constituir a condição indispensável até mesmo da dignidade de ser feliz (KANT, 2009, p. 103).

Os aspectos do sujeito podem ser bons, dado suas próprias características, ainda que não irrestritamente bons, já que, sem uma boa vontade para guia-los, tornar-se-iam ferramentas de ações perversas de toda sorte. A passagem entre aspectos do sujeito e valor relativo das ações exige uma mediação da boa vontade. Contudo, não se segue dessa relação a introdução dos fins universais e da "dignidade de ser feliz" apresentados neste trecho. A boa vontade como aquilo pelo qual se conformam os princípios do agir a fins universais não é apresentada neste trecho, dado que 


\section{Quesidonis Felipe da Silva}

só expusemos as razões pelas quais outros aspectos, intrínsecos e extrínsecos ao sujeito, não podem ser tidos como bons irrestritamente, do que não se segue a conformação a fins. Da mesma forma, de que modo a boa vontade garante a "dignidade de ser feliz" é estranho ao trecho e à argumentação. Durante a apresentação dos dons da fortuna, Kant os reduz justamente à felicidade. Deste modo, a felicidade mesma não pode ser tida como irrestritamente boa, mas, ainda assim, 0 merecimento de ser feliz é tido como ligado à boa vontade.

Estes pontos são elucidados quando Kant define não a boa vontade - 0 que exigiria definir o significado de vontade - mas sim a razão pela qual ela é boa: "a boa vontade é boa, não pelo que efetua ou consegue obter, não por sua aptidão para alcançar qualquer fim que nos tenhamos proposto, mas tão-somente pelo querer" (KANT, 2009, p. 105). Este passo do argumento possui uma estrutura peculiar. Sabemos que há algo chamado vontade, e aquilo que é próprio da boa vontade é ser boa. Para tanto, retira-se dela qualquer efetividade enquanto ação e deixa-se, tãosomente, este bom querer. Neste sentido ela é irrestritamente boa, por não ter a obrigação de efetuar nada em particular, mas sim por este impulso que, mesmo impotente, preservaria seu atributo "bom". Kant chega a dizer que, em relação à boa vontade, a utilidade seria "apenas 0 engaste para poder melhor manuseá-la no comércio comum ou atrair para si a atenção daqueles que ainda não são bastante conhecedores, mas não para recomendá-la a conhecedores e determinar seu valor" (KANT, 2009, p. 105-107).

A questão aqui gira em torno de perceber, uma vez exposto 0 caráter irrestritamente bom da boa vontade, a adequação da razão comum com sua apresentação. Kant parece defender a adequação do conhecimento comum com esta ideia. Mas reconhece, entretanto, a possibilidade de certo tipo de crítica que pode ser feita a essa concepção que, no fundo, só se basearia em uma 
maneira errônea de compreender a associação da razão com a nossa vontade: baseado em um pressuposto finalista, um crítico poderia dizer que, dado que a natureza tudo fez para a realização de um fim, e dada a busca pelos princípios morais, ter-se-ia que a razão se une a vontade tendo como fim, unicamente, a busca da conservação e da felicidade. Este argumento ficou conhecido na literatura pertinente como argumento teleológico. Sua estrutura baseia-se na admissão de uma hipótese finalista pelo adversário, com o objetivo de desviar a função da razão da moralidade para 0 amor de si. Contra este argumento possível, Kant assume o pressuposto finalista do adversário e defende que se a razão se unisse à vontade para assegurar a felicidade, esta união só poderia ser absurda, uma vez que o instinto, na busca pela felicidade, é muito mais eficaz que a razão que, por sua natureza, pondera e questiona, dificultando a busca desta felicidade. Deste modo, tem-se que se a razão está unida à vontade, será para a realização não da felicidade como um fim, mas sim da boa vontade:

[Se] a razão nos foi proporcionada como razão prática, isto é, como algo que deve ter influência sobre a vontade, então a verdadeira destinação da mesma tem de ser a de produzir uma vontade boa, não certamente enquanto meio em vista de outra coisa, mas sim, em si mesma - para 0 que a razão era absolutamente necessária, se é verdade que a natureza operou sempre em conformidade com fins na distribuição das disposições naturais. Portanto, essa vontade não pode ser, é verdade, o único e todo o bem, mas tem de ser o sumo bem (Das höchste Gut) e a condição para todo outro, até mesmo para todo anseio de felicidade [...] (KANT, 2009, p. 113).

Neste trecho, temos uma nova determinação daquilo que é próprio à razão prática, na hipótese de que a natureza possua determinaç̧ões conforme a fins. A razão será prática quando for capaz de ter influência sobre a vontade, e sua determinação final será produzir uma vontade boa em si mesma. Há uma operação racional pela qual uma vontade pode, em hipótese, ser 
determinada enquanto boa, e, se este é o caso, não é estranha a conexão da razão comum com a noção de boa vontade uma vez que, para ela ser boa, basta certa operação racional. Nas segunda e terceira seções deste trabalho buscamos demonstrar que esta operação, acessível à razão comum, é a construção e admissão da lei moral. Para isto, foi preciso explorar a boa vontade, seguindo 0 texto kantiano, através do conceito de dever.

\section{II.}

[Para] desenvolver o conceito de uma vontade altamente estimável em si mesma e boa sem intenção ulterior, tal como já se encontra no são entendimento natural e [que] não precisa tanto ser ensinado quanto, antes pelo contrário, esclarecido, conceito este que está sempre por cima na estimativa do valor restante, vamos tomar para exame o conceito do dever, que contém o de uma boa vontade, muito embora sob certas restrições e obstáculos subjetivos, os quais, porém, longe de ocultá-lo e torná-lo irreconhecível, antes, pelo contrário, fazem com que se destaque por contraste e se mostre numa luz tanto mais clara (KANT, 2009, p. 115).

Kant introduz o conceito de dever no desenrolar e como parte da exposição do conceito de boa vontade. A boa vontade, que já se encontra no "são entendimento natural", isto é, como concebível pela razão comum como condição da ação moralmente válida, foi exposta como irrestritamente boa. Ao concebê-la como já presente na razão comum, Kant admite que ela deva ser antes esclarecida que ensinada. Para seu esclarecimento faz-se necessário o conceito de dever, que "contém o de uma boa vontade, muito embora sob certas restrições e obstáculos subjetivos". Ao afirmar que o conceito de dever contém o de boa vontade, há dois modos de considerarmos essa relação: ou o conceito de boa vontade está contido sob o conceito de dever ou está contido no 
conceito de dever (KANT, 2011, p. 113). No primeiro caso, temos uma relação de extensão, no segundo, de conteúdo. A extensão de um conceito é determinada por suas notas características, sendo assim, razão de conhecer de algo. 0 conteúdo é determinado pelos conceitos parciais que 0 compõem. Ora, a boa vontade pode ser um conceito parcial do conceito de dever, nem por isso todo ser que está sob a ideia de uma boa vontade, está por isso mesmo submetido ao dever, apenas 0 ente racional finito. Daí a afirmação de Kant de que o dever contém a boa vontade, ainda que com obstáculos subjetivos, ou seja, precisamos interpretar o dever como um caso da boa vontade e, através disso, compreender a própria boa vontade.

A introdução dos obstáculos subjetivos é condição da introdução do conceito de dever. A boa vontade é fruto, como vimos, da determinação da razão prática sobre a vontade. Esta determinação só ocorreria de maneira absoluta se a razão prática possuísse pleno domínio sobre a vontade. Porém, tendo em vista o caráter limitado e sensível do ente humano, a razão não possui tal domínio. Em outros trechos da Fundamentação, Kant chamará esta vontade livre das influências da empiria de vontade santa, mas, no caso humano, a ligação com o sensível cria "restrições e obstáculos subjetivos" que impedem a plena determinação da vontade pela razão prática. Deste modo, é necessária outra forma de estabelecer a moralidade em condições humanas. 0 conceito de dever opera como o espaço no qual a boa vontade é posta à razão finita, ainda que com dificuldades próprias. Dificuldades que, não obstante, servem antes para expor com mais precisão aquilo que é próprio das ações com boa vontade, ou seja, das ações morais. Para esta exposição da boa vontade, Kant distingue as ações contrárias ao dever, conformes ao dever e por dever (KANT, 2009, p. 115-117). As ações contrárias ao dever não precisam ser discutidas por já estarem 


\section{Quesidonis Felipe da Silva}

expressamente se opondo ao que poderia haver de moral nas ações. Entre as ações conformes ao dever e as ações por dever é preciso ainda distinguir dois grupos das primeiras, para que a comparação com as segundas seja apropriada. As ações conformes ao dever, mas às quais o sujeito não possui qualquer inclinação, possuem uma clara distinção das ações por dever: quando, por exemplo, um sujeito evita roubar não por dever, mas por temer a punição. Já as ações conformes ao dever às quais o sujeito possui uma inclinação para elas são particularmente complicadas. Kant oferece três exemplos que buscam ilustrar este último caso: (i) a conservação da vida, (ii) a caridade e (iii) a busca da própria felicidade. Todos estes são pensados por Kant como exemplos de dever. Contudo, há uma diferença entre buscá-los ou realizá-los por dever ou por inclinação. Para (i), Kant opõe ao cuidado ansioso que alguns homens têm com a própria vida, fruto de uma inclinação e que não tem "qualquer valor intrínseco, nem a sua máxima qualquer teor moral", o homem que, mesmo com a máxima amargura e desgosto de viver a ponto de desejar a morte, ainda preserva sua vida por dever. Para (ii), temos a oposição entre aquele que é caridoso por inclinação, a qual 0 ato de bondade apraz, e aquele que, mesmo sem qualquer amor especial pela humanidade, continua os atos de caridade por dever. Para (iii), a oposição entre aqueles que buscam a tãosomente felicidade (soma das inclinações) e aqueles que, mesmo sem saúde ou qualquer incentivo de buscar a felicidade, o fazem na medida do possível também por dever. Cada uma desta oposições não busca construir uma distinção entre os atos bons e maus moralmente. Em nenhum momento a exposição aqui apresentada cria um tipo de oposição entre atos morais e imorais dado que, um mesmo ato (conservação da vida, caridade, busca da felicidade) é comum aos dois exemplos. A oposição aqui, portanto, não é propriamente dos atos, mas do princípio 
interno que move o sujeito à realização de determinados atos. É neste ponto da argumentação que Kant introduz as proposições sobre ação moral da seguinte forma:

A segunda proposição é: uma ação por dever tem seu valor moral não no intuito a ser alcançado através dela, mas, sim, na máxima segundo a qual é decidida, logo não depende da realidade efetiva do objeto da ação, mas meramente do princípio do querer, segundo o qual a ação ocorreu, abstração feita de todos os objetos da faculdade apetitiva. (KANT, 2009, p. 125)

Esta passagem da Fundamentação mantêm, em relação à argumentação precedente, uma linha continua. Após a exposição das oposições entre certos tipos de ações e os princípios internos que movem os sujeitos, utilizando os operadores conforme ao dever e por dever, Kant introduz a estrutura conceitual implícita da exposição anterior: a ação por dever tem seu valor na máxima segundo a qual é decidida e as ações conforme ao dever, igualmente, carecem dessa máxima. A abstração dos fins na consideração dos valores morais opera um deslocamento do eixo de consideração que permite perceber por contraste - assim como foi dito por Kant anteriormente aquilo que pode haver de valor moral nas ações. Caso a moralidade fosse baseada nos fins não poderíamos distinguir de forma alguma quando este fim foi alcançado de maneira lícita ou ilícita. Em outros termos, é fácil perceber que a felicidade à custa do sofrimento de outro não possui valor moral, dado o aspecto não moral da ação, seu efeito, contudo, permanece o mesmo. Ao se deslocar para o princípio das ações não se exclui seus resultados, mas tão-somente se opta por um tratamento dos princípios que, de uma forma ou de outra, já são considerados como a fonte do valor moral das ações, mesmo pelo conhecimento racional moral comum. Apesar da continuidade 
argumentativa desta passagem, há, entretanto, problemas textuais que precisam ser enfrentados de maneira mais atenta antes que se possa prosseguir na leitura da Fundamentação. Ora, Kant faz referência a uma "segunda proposição" sem, em nenhum momento, se referir expressamente a uma "primeira proposição". Esta lacuna é um campo fértil de consideração dos comentadores. Reconstruindo algumas destas posições, gostaríamos de sugerir uma leitura viável, tanto ao texto quanto à linha do argumento, que vê na primeira frase da Fundamentação a primeira proposição.

A primeira proposição, justamente por não constar expressamente no texto, recebe diversas propostas de formulação por parte dos comentadores. R. P. Wolff, baseado na argumentação que antecede a apresentação da segunda proposição (a discussão acerca das ações por dever e conforme ao dever), apresenta, como primeira proposição que: "para uma ação possuir valor moral ela deve ser realizada por dever" (WOLFF, 1986, p. 65). Allen Wood e Diete Schönecker, trazendo para a discussão o fato de Kant afirmar que a terceira proposição é consequência das duas anteriores, supõem que é necessário que o conceito de respeito, presente na terceira proposição (que será discutida na terceira seção deste artigo), mas não na segunda, conste na formulação da primeira, deste modo a formulação da primeira proposição seria: "agir por dever seria agir por respeito à lei" (WOOD, SCHÖNECKER, 2014, p. 54-61). Henry Allison, com relação à proposta de Wolff, lembra que ela é a mais comum das propostas para a primeira proposição, mas ela falharia justamente por não observar a alegação de Kant de que a terceira proposição é consequência das duas anteriores (ALLISON, 2011, p. 122). Allison também não admite a proposta de Schönecker e Wood dado que o conceito de respeito não aparece na Fundamentação até a formulação da terceira proposição. Outra possibilidade, criticada por Allison no mesmo ponto que a proposta de Wolff e defendida por A. R. C. Duncan (DUNCAN, 1957, P. 59) e M. Zingano (ZIINGANO, 1989, P. 42), é 
propor a frase de abertura da primeira seção da Fundamentação como sendo a primeira proposição. Segundo Allison, uma boa proposta para a formulação da primeira proposição seria: "Uma boa vontade sob condições humanas é aquela cuja máxima tem um conteúdo moral" (ALLISON, 2011, 122-126).

Se as críticas de Allison às posições de Wolff, Duncan, Zingano, Wood e Schönecker são válidas, sua proposta também não pode ser admitida. Para deslegitimar as propostas de Wolff, Duncan e Zingano, Allison apela para a relação de consequencialidade entre a primeira e segunda proposições em relação à terceira. Dado que estas proposições não carregam o conceito de respeito, sua consequência com a terceira é quebrada. Contudo, a proposta de Wood e Schönecker é criticada, justamente, porque o conceito de respeito não é apresentado antes da terceira proposição, não podendo, do ponto de vista textual, constar na formulação da primeira. Ora, mas a própria proposta de Allison também não recebe em sua estrutura o conceito de respeito. Para não cair neste equívoco, Allison defende que a consequência entre as proposições não deve ser entendida de um ponto de vista lógico, mas argumentativo. Daí a sua proposta pode ser integrada sem dificuldades na argumentação. Mas, se esse é o caso, sua crítica às propostas de Wolff, Zingano e Duncan perde força.

Neste caso, um caminho ao menos plausível é defender a primeira frase da primeira seção da Fundamentação como a primeira proposição (proposta defendida por Zingano e Duncan). Todas as propostas que constroem uma nova formulação do conceito, apesar de coerentes, perdem de vista que a Fundamentação é um texto que foi revisado pelo filósofo. Revisões estas que, apesar de não introduzirem mudanças substâncias, foram os momentos escolhidos pelo filósofo para 


\section{Quesidonis Felipe da Silva}

introduzir palavras e retificar termos. Se este é o caso, algo como uma lacuna textual de um passo tão importante do argumento deixada para trás é, ao menos, pouco provável. Se, de fato, a consequência entre as proposições não é uma consequência lógica como a estrutura de um silogismo, como querem Wood e Schönecker, eleger um momento da argumentação que apresenta a boa vontade (o momento da distinção entre ações por dever e conforme ao dever) não tem, em relação à proposta de Allison, qualquer vantagem. Por outro lado, se pensarmos como primeira proposição que: "não há nada no mundo ou fora dele que se possa pensar como irrestritamente bom, a não ser, tão-somente uma boa vontade", ganhamos por ser um elemento textualmente presente. Por fim, dada a discussão do ponto de partida da investigação e sua relação, enquanto capacidade judicativa em sentido moral, não é estranho que a investigação, textualmente, inicie pela primeira proposição "teórica" que possa ser admitida pela razão comum. Neste caso, 0 incômodo de H. J. Paton apresentado anteriormente - que via algo estranho na investigação ao começar pela boa vontade, não pela explicação do conhecimento moral comum é resolvido justamente porque a estrutura proposta se encaixa não como um juízo de um homem comum, mas como uma proposição acerca das ações morais. Com estes apontamentos, damos sequência a interpretação do texto da Fundamentação.

Como vimos, a boa vontade é fruto da influência da razão prática sobre a vontade. Neste caso, o valor moral da ação não se liga aos fins alcançados pelo sujeito na realização da ação, mas no princípio que determinou a ação. A razão comum é capaz de perceber o valor incondicional da boa vontade e também de perceber a distinção das ações por dever e conforme ao dever, tendo em vista o princípio que as determinam. Agora, se a vontade precisa ser determinada pela razão 
prática para a produção da boa vontade e se esta determinação acarreta a exclusão dos fins que possam ser efetuados, precisamos entender como se dá essa determinação.

[0 valor moral da ação] não pode estar em outro lugar senão no princípio da vontade, abstração feita dos fins que possam ser efetuados por tal ação; pois a vontade está bem no meio entre seu princípio a priori, que é formal, e seu móbile (Triebfeder) a posteriori, que é material, por assim dizer numa bifurcação, e, visto que a vontade tem, no entanto, de ser determinada por alguma coisa, então ela terá de ser determinada pelo princípio formal do querer em geral quando uma ação ocorrer por dever, visto que lhe foi subtraído todo princípio material (KANT, 2009, p. 127, tradução alterada).

Kant introduz uma divisão da vontade em dois princípios de determinação, um a priori, que é caracterizado como formal, e outro a posteriori, caracterizado como material. Ao afastar os fins ou resultados das ações das considerações morais, Kant precisará alegar que, nas ações morais, o móbile material não é o princípio determinante da ação, mas tão-somente o aspecto formal, fruto desta abstração dos efeitos da ação. Agora, se esta determinação formal garante que o princípio que determina a vontade não possua quaisquer fins (que tornam a ação contingente), isso não garante que o ente racional finito possa ser levado a agir tão-somente por ele, dado sua constituição física. Neste caso, é necessário introduzir algo que seja capaz de determinar o sujeito internamente à ação: será este o papel do conceito de respeito.

\section{III.}


"A terceira proposição, enquanto consequência das duas anteriores, eu a exprimiria da seguinte maneira: o dever é a necessidade de uma ação por respeito à lei" (KANT, 2009, p. 127). A introdução do conceito de respeito encerra um ciclo argumentativo que partiu da consideração da boa vontade - considerada nela mesma -, introduziu a realização da boa vontade, mesmo que sob condições humanas, a partir do conceito de dever, mapeou como fonte do valor moral o princípio que determina a ação - não a ação ela mesma - e que, por fim, encontra seu último passo em um sentimento. Kant, ao considerar a forma pela qual as ações ganham seu valor moral, determinou que ela se dava segundo a máxima que as determina. Neste novo passo, ele retoma os pontos anteriores e integra o novo conceito ao dizer que:

uma ação por dever deve pôr à parte toda influência da inclinação e com ela todo objeto da vontade, logo nada resta para a vontade que possa determinála senão, objetivamente, a lei e, subjetivamente, puro respeito por essa lei prática, por conseguinte a máxima de dar cumprimento a uma tal lei mesmo com derrogação de todas as minhas inclinações (KANT, 2009, p. 129).

A esta passagem se une, enquanto esforço argumentativo, a apresentação da determinação da vontade como operação da razão através da representação da lei:

Por isso, nada senão a representação da lei em si mesma - que por certo só tem lugar no ser racional na medida em que ela [a representação da lei], mas não 0 efeito esperado, é o fundamento determinante da vontade - por constituir 0 bem tão excelente a que chamamos moral, o qual já está presente na pessoa mesma que age segundo a representação dessa lei, mas não se deve esperar [que provenha] primeiro de tudo do efeito (KANT, 2009, p. 129-131). 
A representação da lei, que só tem lugar no ser racional, aparece como o fundamento determinante da vontade. Se essa representação só tem lugar no ser racional e, ao mesmo tempo, tem influência sobre a vontade, percebemos como a razão, enquanto razão prática, garante que a boa vontade possa realizar sua função de determinação. A razão prática determinaria plenamente a vontade a partir de um princípio puramente formal se não houvesse a influência das inclinações que interferem nesta determinação, daí porque, para 0 ente racional finito, a boa vontade, - fruto da determinação da razão prática sobre a vontade a partir da representação da lei - se apresenta como dever. Agora, só por se apresentar racionalmente como dever, a representação da lei não garante que realizemos o dever a não ser que algo, este sim ligado a constituição física de maneira ostensiva, possa nos conduzir à sua realização. A representação da lei é o princípio objetivo de determinação da vontade pela razão, o princípio subjetivo é o respeito à lei. Daí a importância do conceito de máxima na filosofia moral kantiana. Apesar do caráter objetivo da lei, aquilo que é propriamente o fundamento da ação é o princípio subjetivo que conduz o sujeito à sua realização. A máxima é o princípio subjetivo que determina essa ação. Contudo, a máxima não deve ser entendida simplesmente como uma adoção momentânea de determinado objetivo. Ela possui determinação universal (allgemein) da vontade tal que abarca não só um ou outro aspecto da vida do sujeito em questão (ROHDEN, 2015, p. 581-582), mas sim sua vida como um todo (BITNNER, 2004, p. 7-25). E a ação só será moral, justamente, quando o sujeito assume a representação da lei como sua máxima, isto é, adota o princípio objetivo como seu princípio subjetivo.

0 conceito de respeito à lei é introduzido neste momento, não como um sentimento obscuro, fruto desta ou daquela influência externa ao sujeito, mas um sentimento autoproduzido 
pela razão. "A determinação imediata da vontade pela lei e a consciência da mesma chama-se respeito, de tal sorte que este é considerado como efeito da lei sobre o sujeito e não como causa da mesma" (KANT, 2009, p. 131). Enquanto sentimento, o respeito terá um objeto, a própria lei, de tal modo que, enquanto consciência da adoção como máxima da lei objetiva, o respeito em nada contradiz a consideração da lei moral como livre de aspectos empíricos: todo interesse moral do ente racional finito será somente o respeito à lei (KANT, 2009, p. 133). Determinado o conceito de respeito à lei ${ }^{3}$, resta discutir que lei é esta. Enquanto tal, dada a estrutura argumentativa seguida por Kant até aqui, esta lei não pode levar em consideração nenhum efeito que se espere de sua aplicação. Também, dado que a vontade foi privada de todo móbil proveniente da sensibilidade, "nada mais resta senão a legislação universal das ações que sirva sozinha de princípio à vontade": "nunca devo proceder de outra maneira senão de tal sorte que eu possa também querer que a minha máxima se torne uma lei universal" (KANT, 2009, p. 133).

A introdução da noção de legislação universal para a apresentação da lei moral reafirma dois aspectos indispensáveis do argumento: sua perspectiva universalista e seu caráter racional. E, foi baseando-se nesse fundamento de racionalidade que a argumentação pode prosseguir de maneira linear em direção a um progressivo afastamento de considerações espúrias à pura

\footnotetext{
${ }^{3}$ Uma última questão acerca do conceito de respeito gira em torno de certas interpretações por parte dos comentadores. Se para Wood e Schönecker não há nada de novo na terceira proposição e na introdução do conceito de respeito, dado que ela só continuaria o conceito de respeito que já estava implícito na "primeira proposição" (WOOD, SCHÖNECKER, 2014, p. 78-80), Allison, por sua vez, percebe uma ambiguidade no conceito de respeito que exige uma divisão do respeito em respeito-agente e respeito-espectador: o primeiro, tomando a lei como sua máxima e motivando à ação diretamente, ao passo que o segundo só indiretamente, da observância da lei nas ações de outros (ALLISON, 2011, p. 128-129). Dada a argumentação anterior, não há porque seguir a leitura de Wood e Schönecker, uma vez que o conceito de respeito só é introduzido na terceira proposição, constituindo assim um acréscimo novo e indispensável ao argumento da obra. Em relação à leitura de Allison, só se faz necessário atentar ao fato de que, por mais que se possa dividir dois aspectos do respeito, de nenhum modo o "exemplo" de uma boa ação pode ser tomado como motivador.
} 
racionalidade, mantendo tão-somente aquilo que é próprio da racionalidade enquanto tal: a forma da universalidade. Esta formulação vale, não somente para este ou aquele caso em particular, mas como critério para a correção de toda ação. Correção esta que se dá no campo racional, não empírico. Este passo completa o objetivo desta seção, dado que "chegamos, no conhecimento moral da razão humana comum, até o seu princípio, o qual, é verdade, ela não se representa em pensamento de maneira tão abstrata numa forma universal, mas que ela tem sempre efetivamente diante dos olhos, usando-o como norma de seu ajuizamento" (KANT, 2009, p. 139). A formulação da lei em seu caráter abstrato explicita seu sentido de dever, ao afirmar que não se deve proceder de outro modo senão aquele em que minha máxima - meu princípio subjetivo do querer - se torne uma lei universal - isto é, seja ele universalmente válido: no exemplo da falsa promessa, ela não se adequa ao caráter universal da vontade justamente porque não atende os critérios estabelecidos pela lei enquanto fórmula legislativa.

Se retomarmos os problemas motivadores deste trabalho, ou seja, qual a legitimidade da universalização da máxima que se opera nesta seção e de que modo as "três proposições", nela apresentadas, podem ser compreendidas como este processo de universalização, percebemos que, por um lado, a legitimidade do processo de universalização se dá com o delineamento dessa instância da vontade em sua mera forma legislativa que, sendo a operação da razão prática, possui a capacidade de influir efetivamente sobre a vontade. Cada uma das proposições introduz um elemento conceitual necessário para esse processo de universalização: a primeira, introduz 0 conceito de boa vontade, que nos leva ao conceito de dever; a segunda, apresenta a máxima, enquanto forma universal, como a fonte do valor moral da ação; a terceira, introduz o conceito de 
respeito, sentimento autoproduzido pela razão, ao se tomar a máxima objetiva como máxima subjetiva para a realização da ação moral. Assim, esperamos ter demonstrado o papel e a centralidade destas proposições, bem como a legitimidade da universalização apresentada nesta seção da Fundamentação.

\section{Referências bibliográficas:}

ALLISON, H. E. Kant's Groundwork of the Metaphysics of Morals. Oxford: Oxford University Press, 2011.

ALMEIDA, G. A. Introdução. In: Immanuel Kant. Fundamentação da metafísica dos costumes. São Paulo: Discurso Editorial, 2009, p. 11-57.

BITTNER, R. Máximas. Trad. de M. L. Engelman e R. P. Severo. Studia Kantiana 5: 7-25, 2004.

DANCAN, A. R. Practical Reason and Morality. A Study of Immanuel Kant's Foundations for the Metaphysic of Morals. London: T. Nelson, 1957.

DELBOS, V. La philosophie pratique de Kant. Paris: PUF, 1969.

KANT, I. Lógica. Trad. G. A. Almeida. São Paulo: Tempo Brasileiro, 2011.

Fundamentação da metafísica dos costumes. Trad. de G. A. Almeida. São Paulo: Barcarolla e Discurso Editorial, 2009

Antropologia de um ponto de vista pragmático. São Paulo: Iluminuras, 2006.

PATON, H. J. The Categorical Imperative. A Study in Kant's Moral Philosophy. Philadelphia: University of Pennsylvania Press, 1971

ROHDEN, V. Notas complementares. In: Immanuel Kant. Crítica da razão prática. São Paulo: Martins Fontes, 2015, pp. 581-582. 
SCHÖNECKER, D.; WOOD, A. Kant's Groundwork for the Metaphysics of Morals: A Commentary. Cambridge, MA: Harvard University Press, 2014.

WOLFF, R. P. The Autonomy of Reason. A Commentary on Kant's "Groundwork of the Metaphysics of Morals". London: Harper Publishers, 1986.

ZINGANO, M. Razão e história em Kant. São Paulo: Brasiliense, 1988. 